\title{
Gross pathological lesions of bovine tuberculosis and efficiency of meat inspection procedure to detect- infected cattle in Adama municipal abattoir
}

\author{
Dechassa Terefe \\ Department of Pathology and Parasitology, College of Veterinary Medicine, Haramaya University, Ethiopia.
}

Accepted 16 August, 2012

\begin{abstract}
A cross-sectional study was conducted at Adama municipal abattoir from February 2010 to May 2011 to estimate the prevalence of bovine tuberculosis (BTB) and to evaluate the efficiency of meat inspection procedure to detect cattle infected with Mycobacterium bovis. The study only involved routine and detailed inspection at slaughter house. Chi-square test and test of agreement (Kappa value) were used to analyze the data. Out of 486 carcasses examined, $33(6.79 \%)$ had lesions suggestive of tuberculosis. Routine abattoir inspection detected only $5(15.15 \%)$ of 33 carcasses with visible lesion, and there was poor agreement $(k=0.14)$ between routine meat inspection and detailed post mortem examination. Anatomically, $67.7 \%$ of the lesions were found in lung and associated lymph nodes, $10.76 \%$ in mesenteric lymph node, and $9.2 \%$ in lymph nodes of the head and the remaining $12.3 \%$ were found in the prescapular, prefemoral and other lymph nodes and organs of the carcass. There was a significant difference $(P<0.05)$ in TB infection rate among different breeds, sex, and body conditions score (BCS). However, no significance difference $(P>0.05)$ was recorded between TB infection rate and ages of the animals. This study suggested that the relatively higher prevalence of BTB and low sensitivity of routine abattoir inspection warrant immediate attention.
\end{abstract}

Key words: Adama, abattoir, bovine tuberculosis.

\section{INTRODUCTION}

Tuberculosis (TB) is an infectious disease caused by mycobacteria that has been a major health risk to man and animals for more than a century. It is widely distributed throughout the world affecting all age groups of humans and animals. In humans, it is responsible for more deaths than any other bacterial disease ever today (Bhatia and Ichpujani, 1994).

Bovine tuberculosis (BTB) is a disease characterized by formation of granulomatous nodules called tubercles whose locations depend largely on the route of infection. In calves, it is usually transmitted by ingestion and lesions involve the mesenteric lymph nodes with possible spread to other organs. In older cattle, infection is usually by the respiratory tract with lesions in the lung and dependent lymph nodes (Carter and Changappa, 1993).

BTB is an endemic disease of cattle in Ethiopia. It has been reported from different regions of the country based on tuberculin test (Ameni et al., 1999; Assegid et al., 2000) and abattoir inspection (Assegid et al., 2004). However, the prevalence of the disease has not been well established because of inadequate disease surveillance and lack of better diagnostic facilities. In 1971, the condemnation rate of carcasses with tuberculosis lied between 1 and $1.5 \%$ in Dire Dawa slaughter house (Teshome, 1995). Gezahegn (1991) compiled a five year (1985 to 1990) synthesis report of meat inspection in six 
abattoirs. Accordingly, from a total of $1,106,412$ cattle slaughtered, generalized TB was the cause of whole carcass condemnation in $0.008 \%$, but with wide differences. Later, Teshome (1995) reported a prevalence of $0.4 \%$ based on the 250,000 cattle slaughtered at Addis Ababa abattoir in 1991. In another preliminary study of bovine TB, Regassa (1999) found a prevalence of $8 \%$ for the cattle slaughtered in Soddo abattoir based on the identification of tuberculosis lesion. None of the post mortem cases however were confirmed. Ameni and Wudie (2003) reported a prevalence of 5.2\% in Nazareth municipality abattoir. Examination at slaughter houses reported lower percentages of TB prevalence than tuberculin tests (Assegid et al., 2004) and this may indicate a high rate of non-specific reaction to tuberculin test.

Bovine tuberculosis is expected to have significant impact on the public health as $95 \%$ of the Ethiopian farmers are still keeping Zebu cattle using the traditional animal husbandry system, which consists of consuming animal product raw and often sharing the same shelter with animals (Laval and Ameni, 2004). Therefore, the objectives this study were to estimate the prevalence of BTB in animals slaughtered in Adama municipality abattoir, to assess the distribution of tuberculous lesions in slaughtered animals, and to evaluate the efficiency of abattoir inspection for the diagnosis BTB.

\section{MATERIALS AND METHODS}

\section{Study area}

The study was conducted, from February 2010 to May 2011, in Adama Town in the Eastern Shoa Zone of Oromia Regional State, Ethiopia. Animals slaughtered in Adama municipal abattoir come from different parts of the country, including Arsi, Bale, Afar, Harar, and Borena areas. The town has one municipality abattoir that supplies the inspected meat to more than 150,000 inhabitants and 82 legally registered butcheries. Each day on average, 60 heads of cattle are slaughtered in the abattoir starting from midnight. The history of all the cattle slaughtered at the abattoir about TB infection is not known and are not tested by the tuberculin test before slaughter. The TB status of the herd or the region from which cattle were brought to abattoir is also not known. Most of the cattle slaughtered in the abattoir were males of adult local zebu, 4 years of age and above which had entered in the feedlots late in their life. They were in fair to very good body condition. Very few numbers of female cattle were also slaughtered in the abattoir. These were cows culled, because of reproductive problems, poor performance and at the end of their reproductive life.

\section{Study design}

The study design followed was a cross-sectional study in which the prevalence of BTB was determined. The efficiency of routine abattoir meat inspection to diagnose TB lesions was also evaluated. A systematic random sampling procedure was used to include animals in the study. In general, 486 cattle and their carcasses were included in the study. This number includes 461 adult males and 26 adult females, and constitutes approximately 5 to 7 cattle for each visit day, which was done four times a week for four months.

\section{Ante mortem examination}

Cattle included in the sample size were examined physically before they are slaughtered. Breed, age, sex, and body condition score (BCS) of the animals were recorded. Additionally, body temperature, pulse rate, respiratory rate, type of nasal discharge (if present), condition of regional lymph nodes, and visible mucous membranes were examined and recorded for individual animals to be slaughtered to support the post-mortem inspection.

\section{Post-mortem examination}

\section{Routine meat inspection}

TB detection was conducted by assistant meat inspector of the abattoir, using the guidelines recommended by the Meat Inspection and Quarantine Division of the Ministry of Agriculture and Rural Development. The inspection involves palpation and incision of the lungs and liver, visual examination of intact organs like kidneys, and palpation and incision of lymph nodes mostly affected by TB such as tracheobronchial, mediastinal, medial retropharyngeal, parotid, prescapular, and prefemoral.

\section{Detailed meat inspection}

Inspection of each of the carcass was undertaken in detail according to Ameni et al. (2007) and Biffa et al. (2010). Particular emphasis was given during examination to certain organs and lymph nodes that were carefully inspected for the presence of suspected BTB lesions. The seven lobes of the two lungs, including the left apical, left cardiac, left diaphragmatic, right apical, right cardiac, right diaphragmatic, and right accessory lobes, were inspected externally and palpated. Then, each lobe was sectioned into $2 \mathrm{~cm}$ thick slices to facilitate the detection of lesions. Similarly, lymph nodes, namely, the parotid, submaxillary, mandibular, medial retropharyngeal, tracheobronchial, cranial and caudal mediastinal, hepatic, mesenteric iliac, precrural, prescapular, supramammary, inguinal, apical, and ischiatic lymph nodes, were sliced into thin sections (circa $2 \mathrm{~mm}$ thick) and inspected for the presence of visible lesions. Moreover, organs such as liver, kidneys, mammary gland and intestines were also thoroughly examined. The cut surfaces were examined under bright light for the presence of abscess, cheesy mass, and tubercles (Corner, 1994). When gross lesions suggestive of BTB were found in any of the tissues, the animal was classified as having lesions.

\section{Data collection}

The individual animal identification number, breed, sex, and age of the animal were recorded. Body condition scoring was made using a method developed for Zebu cattle (Nicholson and Butterworth, 1986). Age category was given by using the dental eruption and wear as described by De Lanta and Habel (1986). The range and frequency of anatomical sites where tuberculosis lesion were detected were also recorded for affected cattle.

\section{Data analysis}

The data collected from the study area was entered into Ms Excel spread sheets and was analyzed by using Intercooled Stata 7. Chisquare test and test of agreement (Kappa-value) methods were used for the analysis of the data. In all the analysis, $\mathrm{P}$-value was held at $<0.05$ for significance. 
Table 1. Comparison of the results of routine and detailed examination.

\begin{tabular}{lccc}
\hline \multirow{2}{*}{ Routine meat inspection } & \multicolumn{2}{c}{ Detailed meat inspection } & \multirow{2}{*}{ Total } \\
\cline { 2 - 3 } & Positive & Negative & \\
\hline Positive & 5 & 0 & 5 \\
Negative & 28 & 453 & 481 \\
Total & 33 & 453 & 486 \\
\hline
\end{tabular}

Sensitivity $=15.15 \% ;$ Kappa $=0.14$.

Table 2. Prevalence of bovine tuberculosis in different breeds of cattle examined.

\begin{tabular}{lcccc}
\hline Breed & No. of animals examined & Positive & Percentage & P-value \\
\hline Arsi & 298 & 20 & 6.92 & \\
Boran & 88 & 10 & 11.4 & 0.047 \\
Harar & 57 & 0 & 0 & \\
Kereyu & 51 & 3 & 5.9 & \\
\hline
\end{tabular}

\section{RESULTS}

The overall prevalence of BTB in cattle slaughtered in Adama municipality abattoir during the study period was $6.79 \%$ based on detailed post mortem examination. Macroscopically, the most common changes seen in the affected organs and/or lymph nodes were the presence of circumscribed yellowish white lesions of various sizes and numbers. Miliary lesions were observed in the lung and liver in 2 of the 33 positive carcasses (6\%). Large encapsulated nodules containing yellowish white exudates were observed in some of the affected organs. There were also active lesions with reddish to black demarcated necrotized areas, particularly on the lymph nodes of the suspected animals, but majority of the lesions collected were calcified.

Using detailed necropsy, 33(6.79\%) carcasses were found to contain visible TB lesions. However, only 5 $(1.02 \%)$ heads of cattle were found to have detectable TB lesions by the routine abattoir inspection (Table 1). Thus, the proportion of lesions detected by detailed necropsy to that of routine abattoir inspection procedure was found to be 6.6:1. The results of this study indicated that the probability of missing an animal with TB lesion during routine abattoir inspection was estimated to be $84.85 \%$. A poor agreement $(K=0.14)$ was recorded between these two procedures. The average number of infected tissues per infected carcass was 1.3 and $72.7 \%$ of the animals had only a single lesion. The distribution and frequency of tuberculous lesions in different organs in cattle affected with mycobacterium is indicated in Tables 4 and 5 , respectively. Lung and its associated lymph nodes are the most affected parts $(67.7 \%)$, followed by mesenteric lymph nodes $(10.76 \%)$, lymph nodes of the head $(9.23 \%)$ and prescapular, prefemoral and other organs and tissues of the carcass (12.30\%) (Table 5).

There was a significant difference $(P=0.047)$ in TB infection rates between the cattle breeds examined, the highest being in the Boran breed (11.4\%) followed by Arsi $(6.92 \%)$ and Kereyu $(5.9 \%)$. The TB infection rate in Harar breed was zero (Table 2).

The study revealed statistically significant difference $\left(\chi^{2}\right.$ $=8.337, \mathrm{P}=0.004)$ in infection rates among males and females, the highest being in females (12\%) as compared to males $(6.5 \%)$. The result of this study also indicated a significant association between the prevalence of the disease and BCS where there was a significant difference $(P=0.003)$ between the two BCS. However, no significant difference $(P=0.069)$ in TB infection rate was recorded between the two age categories of the animals examined (Table 3 ).

\section{DISCUSSION}

This study detected tuberculosis lesions in $6.79 \%$ of cattle examined in Adama municipal abattoir. This prevalence is in agreement with the findings of previous studies done with similar diagnostic methods (Regassa, 1999; Ameni and Wudie, 2003; Teklu et al., 2004). However, the prevalence in this study is relatively lower as compared to the prevalence of the disease in dairy farms in Ethiopia (Ameni and Regors, 1998; Kiros, 1998; Ameni et al., 2001). This is also in line with other studies done in other countries which indicate lower infection rates in beef cattle than in the dairy (Pritchard, 1988).

The lower prevalence in the abattoir could be due to the fact that animals slaughtered in the abattoir are mainly Zebu, which are relatively resistant to BTB. Several studies have also indicated that not all cattle infected with Mycobacterium bovis have gross lesions of tuberculosis that are visible in the tissues examined at slaughter (Whiple et al., 1996). In this regard, many researchers have isolated $M$. bovis through bacteriological 
Table 3. Prevalence of BTB with respect to sex, age, and BCS.

\begin{tabular}{lccccc}
\hline Variable & No. of animals examined & Positive & Percentage & $\chi^{2}$ & P-value \\
\hline Sex & & & & & \\
Male & 461 & 30 & 6.5 & & 0.004 \\
Female & 25 & 3 & 12 & & \\
& & & & & \\
Age & & & & & \\
$<6$ years & 83 & 32 & 7.94 & 8.337 & 0.069 \\
$>6$ years & 403 & & & & \\
BCS & & 3 & 1.9 & & \\
Fat & 160 & 30 & 9.2 & & 0.003 \\
Medium & 326 & & & & \\
\hline
\end{tabular}

Table 4. Distribution of TB lesions in organs of cattle slaughtered.

\begin{tabular}{lcc}
\hline Organ & No. of specimens & Percentage \\
\hline Lung & 4 & 9.3 \\
Tracheobronchial & 13 & 30.03 \\
Mediastinal & 13 & 30.03 \\
Medial retropharyngeal & 4 & 9.3 \\
Mandibular Ln & 2 & 4.65 \\
Mesenteric Ln & 4 & 9.3 \\
Prescapular Ln & 1 & 2.32 \\
Prefemoral Ln & 1 & 2.32 \\
Liver & 1 & 2.32 \\
Total & 43 & 100 \\
\hline
\end{tabular}

Table 5. Frequency of tuberculous lesions in different organs of cattle examined.

\begin{tabular}{lcc}
\hline Anatomical site & No. of tuberculous lesions & Percentage \\
\hline Tracheobronchial lymph node & 19 & 29.23 \\
Mediastinal lymph node & 17 & 26.15 \\
Medial retropharyngeal lymph node & 4 & 6.15 \\
Mandibular lymph node & 2 & 3.07 \\
Mesenteric lymph node & 7 & 10.76 \\
Lung & 8 & 12.3 \\
Liver & 2 & 3.07 \\
Prescapular lymph node & 4 & 6.15 \\
Prefemoral lymph node & 2 & 3.07 \\
Total & 65 & 100 \\
\hline
\end{tabular}

culture from lymph nodes and lungs with no visible lesions (Corner, 1994).

In this study, the sensitivity of routine abattoir inspection is found to be $15.15 \%$ with Kappa $=0.14$ which shows that the routine abattoir necropsy procedure failed to detect $84.85 \%$ of tuberculous animals. This low sensitivity could be due to the low number of tissues inspected and the relatively high proportion of small lesions which could not be detected in routine inspection. Therefore, this finding indicates that the abattoir inspection procedures need to be improved, given that the sensitivity of gross postmortem examination is affected by the method employed and the anatomical sites examined (Corner, 1994). In line with this, several studies have reported that the prevalence of tuberculosis infection increases with enhanced meat inspection 
procedures such as multiple slicing of organs and lymph nodes (Corner, 1994; Whiple et al., 1996).

Previous studies have reported that the detailed necropsy alone detected above $84 \%$ of all lesions (Corner, 1994; Teklu et al., 2004). Therefore, detailed meat inspection can be considered as satisfactory procedure to detect tuberculous lesion.

In this study, gross tuberculosis lesions were found most frequently in the lymph nodes of thoracic cavity $(67.7 \%)$, mesenteric lymph node $(10.8 \%)$, followed by lymph nodes of the head $(9.2 \%)$ and prescapular, prefemoral and other organs of the carcass $(12.2 \%)$. This finding is consistent with previous studies done in Ethiopia (Firdissa, 2006; Nesredin, 2006) where 70 and $70.7 \%$ TB lesions were reported in lungs and associated lymph nodes, respectively. However, the distribution of TB lesion in the current study significantly differs from reports from Mexico (Miliano-suazo et al., 2000) where $49.2 \%$ of lesions involved the retropharyngeal lymph node. Corner (1994) has reported that up to $95 \%$ of cattle with visible TB lesions could be identified by examination of the lung and associated lymph nodes. This finding indicates that inhalation might be the principal route of TB infection in cattle. Therefore, during post mortem examination, focus should be given on lungs and associated lymph nodes. However, the presence of lesions in mesenteric lymph nodes indicates that the infection occurs through ingestion (Radostits et al., 1994).

The average number of infected tissue per infected carcasses was 1.3 and $72.7 \%$ of the animals that had only a single lesion. This finding complies with previous reports (Corner, 1994, Teklu et al., 2004; Nesredin, 2006) which emphasizes the possibility of missing a tuberculous carcass during routine inspection procedures. The failure to detect a lesion during abattoir inspection has the greatest significance in cattle with single lesion, since if the lesion is missed there is no further chance of detecting the disease in the animal.

The significant difference $(P=0.047)$ among the different local breeds of animals seems to be a reflection of management than breed, since most of the cattle fattened in a small scale fattening and large scale feedlots in the study area were mostly Boran and Arsi breeds signifying the role of intensification in tuberculosis infection. The study showed a significant difference in the prevalence $(P=0.004)$ between the two sexes being higher in females (12\%) as compared to males (6.5\%). This is possibly due to their longer productive life and other stressful factors (such as pregnancy, parturition, lactation, etc) associated with female animals (Milianosuazo et al., 2000; Teklu et al., 2004). There is a statistically significant difference in the prevalence of the disease $(P=0.003)$ between BCS, the prevalence being the highest in medium body condition (9.2\%) as compared to fatty animals (1.9\%). This could indicate the wasting nature of the disease. The present result is consistent with previous reports which indicated that animals with good BCS have relatively good immunolo- gical response to the infectious agent than animals with medium BCS (Radostits et al., 1994). The proportion of tuberculosis infection was lower for less than 6 years age groups as compared to greater than 6 years age group categories; although, the difference is not statistically significant. This may be due to their young age or too early for them to develop tuberculosis lesion even if they were infected as compared to the old groups, which are managed in closed spaces. In addition, it may also be due to the chronic nature of the disease where the animals acquired the infection at young age and develop the clinical sign at old age or when the immune system of the animal is compromised (Radostits et al., 1994).

\section{REFERENCES}

Ameni G, Roger F (1998). Study on the epidemiology of bovine tuberculosis in dairy farms (Debre zeit and Ziway, Ethiopia). In proceeding of the $12^{\text {th }}$ conference of Ethiopian veterinary association.

Ameni G Wudie A (2003). Preliminary study on bovine tuberculosis in Nazareth municipality abattoir of centeral Ethiopia. Bull. Anl. Health. Prod. Afr. 51,125-132.

Ameni G, Miorner H, Roger F, Tibbo M (1999). Comparison between comparative tuberculin and interferon gamma tests for the diagnosis of bovine TB in Ethiopia. Trop. Anim. Health. Prod. 32:267-276.

Ameni G, Ragassa A, kassa T, Medhin G (2001). Survey of bovine tuberculosis and its implications to cattle raising families in walaita soddo, Southern Ethiopia. Ethiopia J. Anim. Prod. 1(1):55-62.

Ameni G, Aseffa A, Engers H, Young D, Gordon S, Hewinson G, Vordermeier M (2007). High Prevalence and Increased Severity of Pathologyof Bovine Tuberculosis in Holsteins Compared to Zebu Breeds under Field Cattle Husbandry in Central Ethiopia. Clin. Vaccine Immunol., pp: 1356-1361.

Assegid B, Lubke-Beeker A, Lemma E, Tadele K, Britton S (2000). Bovine TB: a cross sectional and epidemiological study in and around Addis Ababa. Bull. Anim Health Prod. Afr. 48:71-80.

Assegid B, Woldesenbet Z, Yimer E, Lemma E (2004). Evaluation of abattoir inspection for the diagnosis of M.bovis infection in cattle slaughtered at Addis Ababa abattoir. Trop. Anim. Health. Prod. 36(6):537-546.

Bhatia R, Ichpujani RL (1994). Mycobacterium. In: Essentials of Medical microbiology. 1st Ed. Medical publishers, PLTD, New, Delhi. pp. 258292

Biffa D, Bogale A, Skjerve E (2010). Diagnostic efficiency of abattoir meat inspection service in Ethiopia to detect carcasses infected with Mycobacterium bovis: Implications for public health. BMC Public Health 10:462.

Carter GR, Changappa MM (1993). Microbial disease. A veterinary guide to laboratory diagnosis. Lomastats. pp.123-128.

Corner LA (1994). Post mortem diagnosis of M. bovis infection in cattle. Vet. Microbiol. 1(40):53-63.

De-Lahunta A, Habel RE (1986). Teeth. Applied veterinary Anatomy. USA. W. B. Sounders Company. pp. 4-16.

Firdissa R (2006). Preliminary study on bovine tuberculosis in and around Sululta town, North shoa zone of Oromia, Addis Ababa University, Faculty of Vetrinary Medicin, DVM thesis.

Gezahegn A (1991). Analysis of economic losses due to bovine tuberculosis. Annual report of Ministry of Agriculture. Addis Ababa, Ethiopia.

Kiros T (1998). Epidemiology and Zonotic importance of bovine tuberculosis in selected site of Eastern shoa, Ethiopia, Faculty of Veterinary Medicine, Addis Ababa University and Free University of Barlin, MSC thesis.

Laval G, Ameni G (2004). Prevalence of bovine tuberculosis in zebu cattle under traditional animal husbandry in Boji District of western Ethiopia. Revue. Med. Vet. 155(10):494-499.

Miliano-suazo F, Salmar MD, Ramirez C, Payeur JB, Rhyan SC, Santillan M (2000). Identification of TB in cattle slaughtered in 
Mexico. Am. J. Vet. Res. 61:86-7.

Nesredin H (2006). Cross section study of BTB in Butajira municipality abattoir, Southern Ethiopia, Addis Ababa University, Faculty of Veterinary Medicine, DVM thesis.

Nicholson MJ, Butterworth MH (1986). A guide to condition scoring of zebu cattle. ILCA, Addis Ababa, Ethiopia.

Pritchard DG (1988). A century of bovine tuberculosis 188-1988. Conquest and controversy. J. Comp. Pathol. 99:357-387.

Radostits OM, Blood DC, Gay CC (1994). Veterinary Medicine. A text book of the diseases of cattle, sheep, pigs, goats and horses. 9th ed. London. Ballier Tindals. pp. 830-838.

Regassa A (1999). Preliminary study in BTB in Walaita soddo, southern Ethiopia. Addis Ababa University, Faculty of Veterinary Medicine, DVM thesis, Debre-Zeit. p. 33.
Teklu A, Asseged B, Yimer E, Gebeyehu M, Woldesenbet Z (2004). Tuberculous lesions not detected by routine abattoir inspection: the experience of the Hossana municipal abattoir, Southern Ethiopia. Rev. Sci. Tech. off int. Epiz. 23(3):957-964.

Teshome Y (1995). Ethiopia. Regional and country states reports in: $M$. bovis infection in animals and humans. lowa state university press. pp. 273-277.

Whipple LD, Boline AC, Miller MJ (1996). Distribution of lesion in cattle infected with mycobacterium bovis. J. Vet. Diagn. Invest. 8:351-354. 